NASA/TM-2009-215664

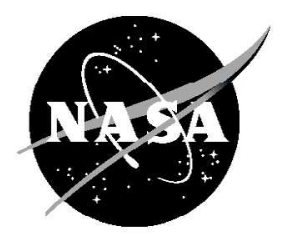

Moisture-Induced Delayed Alumina Scale Spallation on a Ni(Pt)Al Coating

James L. Smialek

Glenn Research Center, Cleveland, Ohio 


\section{NASA STI Program . . . in Profile}

Since its founding, NASA has been dedicated to the advancement of aeronautics and space science. The NASA Scientific and Technical Information (STI) program plays a key part in helping NASA maintain this important role.

The NASA STI Program operates under the auspices of the Agency Chief Information Officer. It collects, organizes, provides for archiving, and disseminates NASA's STI. The NASA STI program provides access to the NASA Aeronautics and Space Database and its public interface, the NASA Technical Reports Server, thus providing one of the largest collections of aeronautical and space science STI in the world. Results are published in both non-NASA channels and by NASA in the NASA STI Report Series, which includes the following report types:

- TECHNICAL PUBLICATION. Reports of completed research or a major significant phase of research that present the results of NASA programs and include extensive data or theoretical analysis. Includes compilations of significant scientific and technical data and information deemed to be of continuing reference value. NASA counterpart of peer-reviewed formal professional papers but has less stringent limitations on manuscript length and extent of graphic presentations.

- TECHNICAL MEMORANDUM. Scientific and technical findings that are preliminary or of specialized interest, e.g., quick release reports, working papers, and bibliographies that contain minimal annotation. Does not contain extensive analysis.

- CONTRACTOR REPORT. Scientific and technical findings by NASA-sponsored contractors and grantees.
- CONFERENCE PUBLICATION. Collected papers from scientific and technical conferences, symposia, seminars, or other meetings sponsored or cosponsored by NASA.

- SPECIAL PUBLICATION. Scientific, technical, or historical information from NASA programs, projects, and missions, often concerned with subjects having substantial public interest.

- TECHNICAL TRANSLATION. Englishlanguage translations of foreign scientific and technical material pertinent to NASA's mission.

Specialized services also include creating custom thesauri, building customized databases, organizing and publishing research results.

For more information about the NASA STI program, see the following:

- Access the NASA STI program home page at http://www.sti.nasa.gov

- E-mail your question via the Internet to help@ sti.nasa.gov

- Fax your question to the NASA STI Help Desk at $443-757-5803$

- Telephone the NASA STI Help Desk at 443-757-5802

- Write to: NASA Center for AeroSpace Information (CASI) 7115 Standard Drive Hanover, MD 21076-1320 
NASA/TM-2009-215664

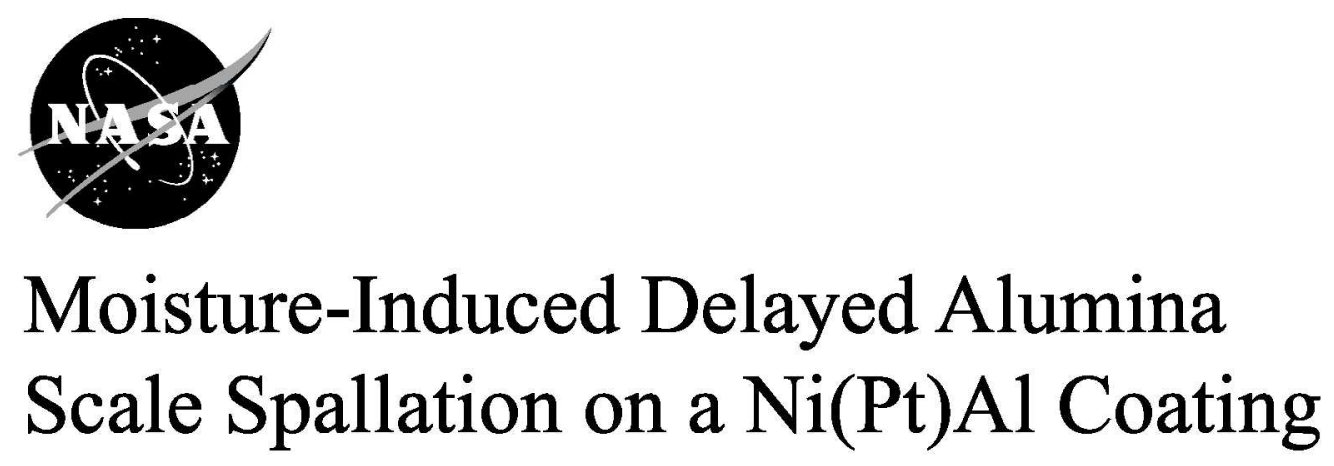

James L. Smialek

Glenn Research Center, Cleveland, Ohio

National Aeronautics and

Space Administration

Glenn Research Center

Cleveland, Ohio 44135 


\section{Acknowledgments}

The author is grateful for SEM/EDS analyses by Dr. A. Garg, NASA Glenn Research Center, insightful discussions with V.K. Tolpygo, and helpful comments from K.S. Murphy, B. Gleeson, B.A. Pint, and P.Y. Hou. This work was initiated from support by Dr. Kang Lee, Rolls Royce and Donna Ballard, WPAFB as part of a coatings life prediction study under the Metals Affordability Initiative.

Trade names and trademarks are used in this report for identification only. Their usage does not constitute an official endorsement, either expressed or implied, by the National Aeronautics and Space Administration.

This work was sponsored by the Fundamental Aeronautics Program at the NASA Glenn Research Center.

Level of Review: This material has been technically reviewed by technical management.

Available from

NASA Center for Aerospace Information 7115 Standard Drive

Hanover, MD 21076-1320
National Technical Information Service 5285 Port Royal Road Springfield, VA 22161

Available electronically at http://gltrs.grc.nasa.gov 


\title{
Moisture-Induced Delayed Alumina Scale Spallation on a Ni(Pt)Al Coating
}

\author{
James L. Smialek \\ National Aeronautics and Space Administration \\ Glenn Research Center \\ Cleveland, Ohio 44135
}

\begin{abstract}
Delayed interfacial scale failure takes place after cooling for samples of a Ni(Pt)Al-coated CMSX4 single crystal superalloy, cycled at $1150^{\circ} \mathrm{C}$ for up to $2000 \mathrm{hr}$. One sample exhibited premature coating grain boundary wrinkling, alumina scale spallation to bare metal, and a final weight loss of $3.3 \mathrm{mg} / \mathrm{cm}^{2}$. Spallation under ambient conditions was monitored with time after cooldown and was found to continue for $24 \mathrm{hr}$. This produced up to $0.05 \mathrm{mg} / \mathrm{cm}^{2}$ additional loss for each hold, accumulating $0.7 \mathrm{mg} / \mathrm{cm}^{2}$ (20 percent of the total) over the course of the test. After test termination, water immersion produced an additional $0.15 \mathrm{mg} / \mathrm{cm}^{2}$ loss. (A duplicate sample produced much less wrinkling and time dependent spalling, maintaining a net weight gain.) The results are consistent with the general phenomena of moisture-induced delayed spallation (MIDS) of mature, distressed alumina scales formed on oxidation resistant $\mathrm{M}-\mathrm{Al}$ alloys. Relative ambient humidity is discussed as the factor controlling adsorbed moisture, reaction with the substrate, and hydrogen effects on interface strength.
\end{abstract}

\section{Introduction}

Platinum modified aluminides are widely used as oxidation resistant coatings or bond coats for thermal barrier coatings (TBC) on single crystal superalloy turbine blades. They are noted for forming protective $\alpha-\mathrm{Al}_{2} \mathrm{O}_{3}$ scales with greater longevity and adherence to the coating than for similarly formed aluminides without Pt. The exact role Pt plays is actively being studied. Early metallurgical treatises focused on the diffusional stability afforded by $\mathrm{Ni}(\mathrm{Pt}) \mathrm{Al}$ coatings due to the great affinity $\mathrm{Pt}$ has for $\mathrm{Al}$ and a decreased tendency to deplete $\mathrm{Al}$ by interdiffusion with the substrate (Ref. 1).

These and related phenomena have been detailed in many subsequent studies by Gleeson et al., as recently reviewed in a comprehensive treatise (Ref. 2). Here it is described that while Pt actually increases aluminum diffusivity $\mathrm{D}_{\mathrm{Al}}$, it reduces the activity $\mathrm{a}_{\mathrm{Al}}$, thus influencing uphill diffusion of $\mathrm{Al}$ from the substrate into a Ni-Pt-Al coating and countering the detrimental $\mathrm{Al}$ depletion caused by interdiffusion (Refs. 3 and 4). Pt additions also broaden the field for stable alumina formation on a ternary oxidation map to include lower $\mathrm{Al}$ contents and phases (i.e., Pt reduces the critical Wagner solute content $\mathrm{N}_{\mathrm{Al}}{ }^{*}$ for healing scales to form) (Ref. 2). This stems from the tendency for Pt to replace Ni in the lattice and present a reduced effective $\mathrm{Ni} / \mathrm{Al}$ surface composition and reduced transient oxidation. It also results from the reduced oxygen solubility/permeability when $\mathrm{Pt}$ is added to Ni-Al alloys, thus discouraging detrimental internal oxidation with respect to an external healing layer of alumina (Ref. 3). These beneficial effects would be magnified from potential Pt surface segregation (Ref. 5).

Other beneficial mechanisms are suggested by the compelling observations that Pt diminishes sulfur surface and interfacial segregation. It consequently encourages stronger interfacial strength (toughness) and reduces interfacial void formation resulting from the low surface energy of sulfur (Refs. 6 to 10). Another contributing factor is the exceptionally strong bond formed between pure $\mathrm{Pt}$ and $\mathrm{Al}$ atoms in $\mathrm{Al}_{2} \mathrm{O}_{3}$ (Refs. 11 to 13). However, Pt enrichments do not seem to dominate the actual alumina - Ni(Pt)Al interface for $\beta$-NiAl (Ref. 7). In fact, the Pt effects on segregation, void growth, and interface strength are quite complex and depend considerably on the Ni-Al stoichiometry and alloy phase, as summarized in the recent review of interfacial segregation by Hou (Ref. 14). In general, void formation and sulfur interfacial segregation become more appreciable as the $\mathrm{Al}$ content is reduced. Here Pt may benefit depleted $\beta$-NiAl 
by producing an $\mathrm{Al}$ interface enrichment, allowing the preferred behavior more typical of the stoichiometric alloy. Additionally, the crystallographic orientation of $\beta$-NiAl has been shown to influence both sulfur segregation and the degree of interfacial void formation (Ref. 8), remarkably allowing voids to form on low indice planes of even desulfurized or Y-doped Ni40A15Cr (Ref. 15).

Despite outstanding oxidation behavior as a bulk material, an issue specific to aluminide coatings is a propensity to deform, especially when cycled. In one description, this phenomenon (ratcheting) (Ref. 16) results from the CTE mismatch between the scale and substrate and an unrecoverable creep strain that occurs during cycling from the hysteresis in thermal stresses. This roughness, coupled with as-processed grain boundary ridges in the coating, produces stress concentrations and a normal tensile stress to the scale. Preferred failure sites and interface crack initiation under a TBC are the result. Thus, scale adhesion remains a concern and is especially critical for TBC applications.

While alumina scale adhesion is normally discussed in terms of sulfur content and interface segregation, along with reactive element and Pt contents, an auxiliary chemical factor exists in the environment, moisture. Generally, moisture effects are observed for at-risk scales, i.e., those that have just enough adherence to be retained by a conventional thermal cycle stress, but may delaminate upon extra duress. Thus, for example, scales formed at intermediate sulfur contents or thick scales with exceptionally high strain energies may be especially susceptible to moisture effects. These phenomena have been directly illustrated for various alloys in a number of early studies (Refs. 17 to 21); the results and viewpoints from our laboratory have been summarized in (Refs. 22 and 23).

One aspect of moisture-induced delayed spallation (MIDS), since the scale has been initially retained upon cooldown, is the time dependent nature. MIDS is most evident when the spallation event is intentionally triggered by the initial exposure to moisture (e.g., moist breath or water immersion). However, holding the material at ambient atmospheric humidity or submerged in water is also known to cause progressive time dependent delamination of alumina scales, proceeding for times up to $24 \mathrm{hr}$ (Refs. 24 and 25). Indeed, interfacial buckle growth has been directly monitored for a sample while observed under a microscope (Ref. 26). The implications on TBC failure have been drawn, and many studies extend the concept to include unintentional (Refs. 24, 26 to 29) or intentional (Ref. 30) moistureassisted TBC delamination. The latter recently includes videos of water-induced failure of pre-oxidized TBC's on coupons (Refs. 31 and 32) and on commercial turbine blades (Refs. 33 and 34).

Returning to the specific case of aluminide coatings, oxidation in 0.1 and $0.3 \mathrm{~atm} \mathrm{H}_{2} \mathrm{O}$ air has been found to increase the amounts of weight loss in $1100^{\circ} \mathrm{C}$ cyclic tests of simple aluminides with increase in p $\left(\mathrm{H}_{2} \mathrm{O}\right)$ (Refs. 21 and 35). However the same effect was not especially evident for the more oxidation resistant $\mathrm{Ni}(\mathrm{Pt}) \mathrm{Al} \mathrm{Pt}$-modified coatings. One can expect that this effect will be enhanced by surface deformation by rumpling and degree of cycling.

The purpose of the present paper is to again call attention to the time dependence of alumina scale spallation, but for the specific case of commercial Ni(Pt)Al coatings. This occurs when mature scales are subjected to normal laboratory room conditions at ambient temperatures and local humidity, as normally encountered during conventional sample weighing and examination procedures. Attention is paid to coating grain boundary ridges and associated deformation, since spallation appears to be closely related to such features. Because the material studied was a widely-used bondcoat on single crystal superalloys, such phenomena are relevant to turbine applications regarding cyclic testing protocols for delayed oxidation and TBC failures.

\section{Experimental}

Coupons of superalloy (CMSX4) were machined from $\sim 1 / 8$ by 1 by 6 in. cast single crystal slabs (PCC) and coated with a commercial Ni(Pt)Al aluminide coating (MDC-150L, Howmet Corporation, Whitehall, MI), all from the same ingot and coated in the same batch. (They were provided by Dr. Kang Lee, Rolls-Royce Corp., Indianapolis, IN, as part of a Metals Affordability Initiative (MAI) study, sponsored by WPAFB, Donna Ballard, Program Manager). Briefly, the Pt was electrodeposited to a thickness of about $5^{+} \mu \mathrm{m}$ and aluminized in a low activity CVD process. 
The samples were approximately $3.2 \mathrm{~mm}$ by $1.27 \mathrm{~cm}$ by $2.54 \mathrm{~cm}$, with a $2.3 \mathrm{~mm}$ diameter hanger hole at one end, with approximately $9.1 \mathrm{~cm}^{2}$ surface areas, weighing approximately $9 \mathrm{~g}$ each. They were ultrasonically cleaned in detergent, rinsed in water then ethanol, and dried. Samples were cyclically oxidized at $1150^{\circ} \mathrm{C}$, suspended by Pt hang wires in a vertical, 6 alumina tube furnace, using a 60 min. heating cycle and a $20 \mathrm{~min}$. cooling cycle for 2000 cycles. Cycling was accomplished by a pneumatic cylinder actuated assembly, controlled by electronic timers and counters. The furnace control temperature was constant, remaining within 1 to $2^{\circ} \mathrm{C}$ throughout the test. Hot zone variations ranged up to $5^{\circ} \mathrm{C}$, depending on the individual tube. During each cooling cycle, the samples were retracted into a baffled chamber above the furnace, providing some barrier to direct thermal drafts. However, the environment was still relatively warm and dry, maintaining $\sim 100^{\circ} \mathrm{C}$. For example, the chamber equilibrated at $105^{\circ} \mathrm{C}$ when the furnace lab air was $17^{\circ} \mathrm{C}$ or $124^{\circ} \mathrm{C}$ when the lab was $22^{\circ} \mathrm{C}$.

Samples were weighed on an analytical balance over a graduated time schedule $(1,2,5,10,20,40$, $60, \ldots 500,550,600, \ldots 1000,1100,1200, \ldots 2000 \mathrm{hr})$. It is shown that weighing automatically provides exposure to a considerably higher relative humidity of the balance room, on the order of 70 percent. It will be shown later that this specimen transfer from the furnace area to the balance results in exposure to about $40 \mathrm{x}$ increase in relative humidity, simply because the saturation level at $\sim 100{ }^{\circ} \mathrm{C}$ is that much greater than at room temperature.

Since we are concerned with small amounts of additional spallation, occurring well after the cooling cycle, some discussion about measuring small weight changes is warranted. The balance sensitivity was $0.01 \mathrm{mg}$. However drift was much greater than this, depending for example on the ambient temperature, humidity, and, more importantly, on any thermal instability impacting the balance. The latter was partially addressed by an outer plexi-glass balance chamber (with access doors) surrounding the balance. Also, it was insured that the samples were fully cooled to ambient conditions (generally $15 \mathrm{~min}$. or longer) before weighing (except for the special time-dependent tests discussed later).

A key step was to always rezero the balance and obtain a calibration weight from a $10.00000 \mathrm{gm}$ standard before each weight. This provided an unchanging reference mass against which any balance drift changes could be corrected for each individual measurement. Over the course of the 9 month test, the standard varied over a maximum range of $0.25 \mathrm{mg}(\sim 10.00008 \pm 0.00004 \mathrm{~g}$ average of about 110 measurements made over the duration of the test). For the $9 \mathrm{~cm}^{2}$ samples used, the standard deviation of this repeated reference measurement would translate into a standard error of sample measurement of less than $0.005 \mathrm{mg} / \mathrm{cm}^{2}$.

After 750 cycles, when spontaneous spallation became apparent, multiple measurements were made over time to track any delayed spallation. For special time-dependent tests, weights were recorded for the first few minutes and hours, up to one day at ambient. Exposure to additional moisture (1-hr water immersion) was performed at the end of the $2000 \mathrm{hr}$ test. Optical macrographs were obtained over the course of the test to document overall spallation patterns, while SEM/EDS was performed at the end of the test to reveal scale morphology and spallation patterns.

\section{Results}

One as-received sample was characterized by electron microprobe WDS scans (Ref. 36). The ascoated thickness, measured from the surface to the included alumina particles (from the initial grit blast surface prep), was $37 \pm 1 \mu \mathrm{m}$. Composition varied somewhat across the layer, but was nominally $50 \mathrm{Ni}$ $8 \mathrm{Co}-8 \mathrm{Pt}-35 \mathrm{Al}-4 \mathrm{Cr}-0.5 \mathrm{Ta}$ at.\%. This compares to previous work reporting $45 \mathrm{Ni}-3.5 \mathrm{Co}-6 \mathrm{Pt}-44 \mathrm{Al}$ $-1.5 \mathrm{Cr}$ or $46.5 \mathrm{Ni}-4.5 \mathrm{Co}-5.5 \mathrm{Pt}-39.6 \mathrm{Al}-3.6 \mathrm{Cr}-0.2 \mathrm{Ta}-0.1 \mathrm{~W}$ for this coating on Rene' N5 (Refs. 46 and 48). Some of TCP phases lie within the coating, above the diffusion zone + TCP region. The latter was an additional $30 \mu \mathrm{m}$ thick. The surface morphology can be seen in Figure 1, where grain boundary ridges can be discerned. These are typical of the often observed grain boundary ridges associated with CVD Ni(Pt)Al coatings (Refs. 9 and 35). Crystallographically aligned surface striations and pits are also evident, presumably an artifact of the CVD process and environment. The EDS response of the overall 


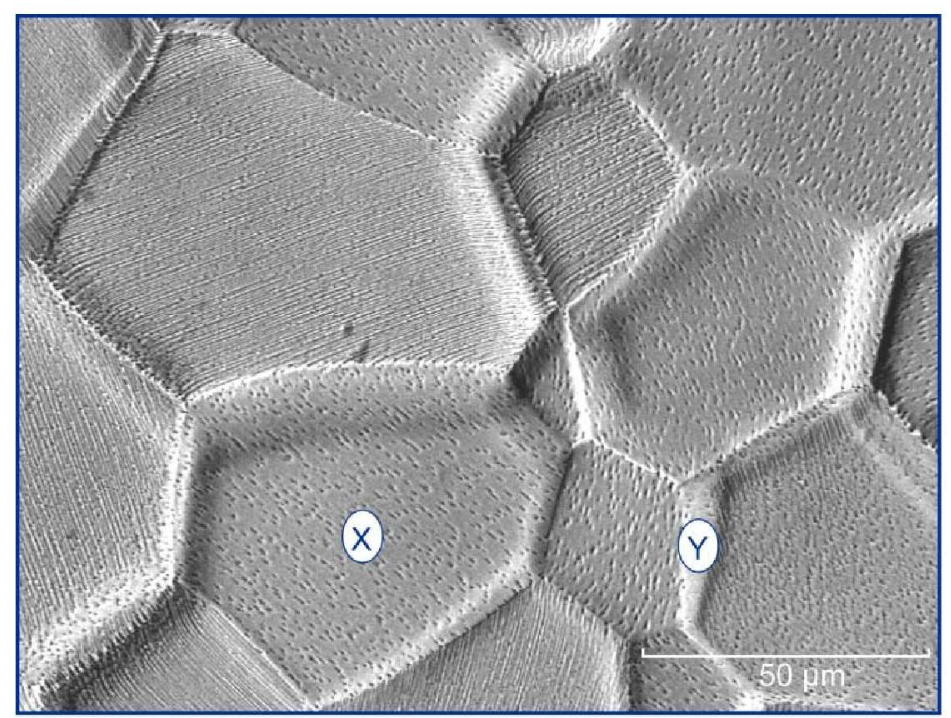

Figure 1.-SEM micrograph of as-coated $\mathrm{Ni}(\mathrm{Pt}) \mathrm{Al}$ surface showing grain boundary ridges, surface striations, and pits.

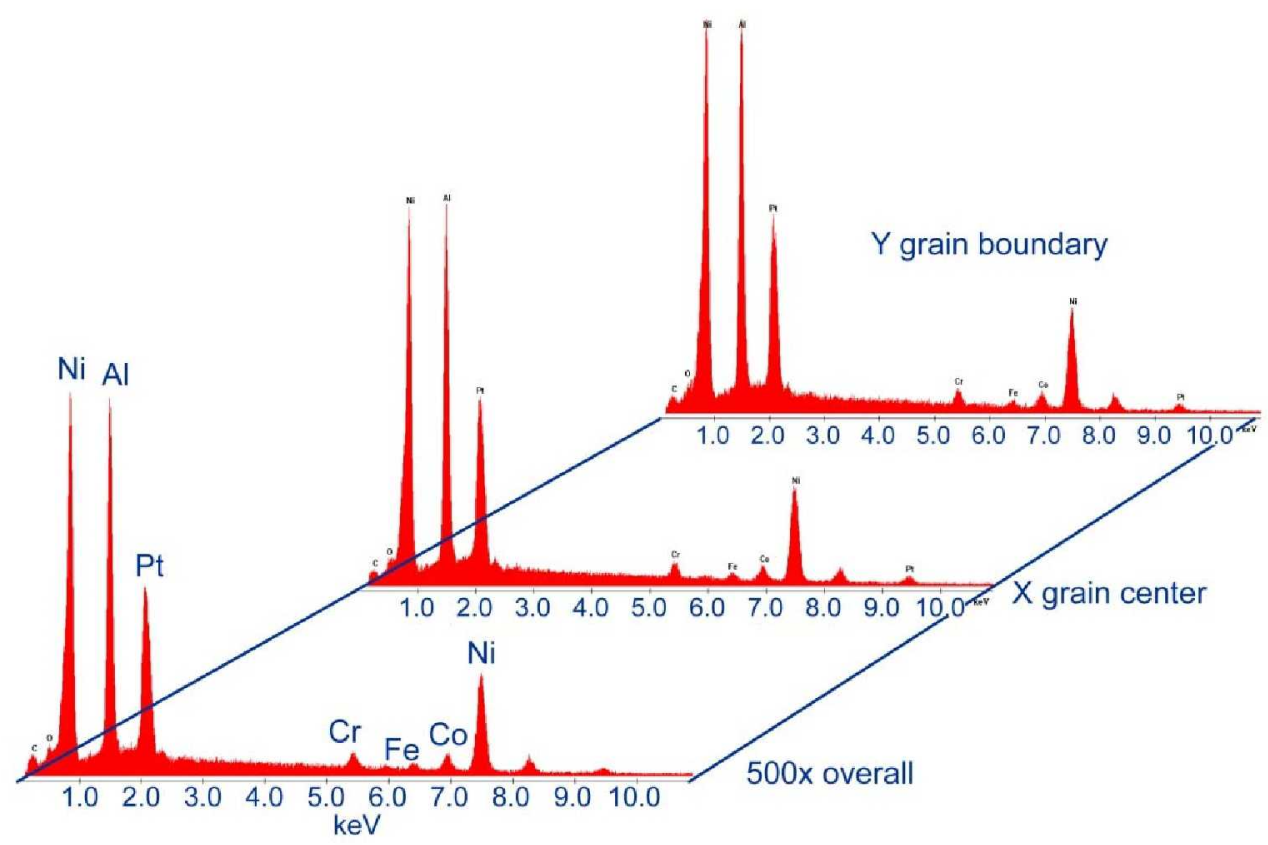

Figure 2.-EDS response from overall, grain center $(X)$, and grain boundary $(Y)$ of figure 1 .

coating, grain interiors, and grain boundaries was generally similar, showing basically uniform amounts of $\mathrm{Ni}, \mathrm{Pt}, \mathrm{Al}$ with a small amount of $\mathrm{Cr}, \mathrm{Fe}$, and $\mathrm{Co}$, Figure 2 . However, no analyses were performed on the actual oxidation coupons before testing.

\section{Weight Change and Delayed Spallation}

The overall $1150{ }^{\circ} \mathrm{C}$ total weight change behavior (due to normal cycling and any delayed spallation) is shown in Figure 3. The response of sample 1150-2 indicates a fairly typical increase to a maximum of $0.8 \mathrm{mg} / \mathrm{cm}^{2}$ at $460 \mathrm{hr}$, followed by a more or less linear loss rate to $-3.3 \mathrm{mg} / \mathrm{cm}^{2}$. A nominally duplicate sample, $1150-4$, increased to a maximum of $0.5 \mathrm{mg} / \mathrm{cm}^{2}$ at $1350 \mathrm{hr}$ and displayed a very small spallation 


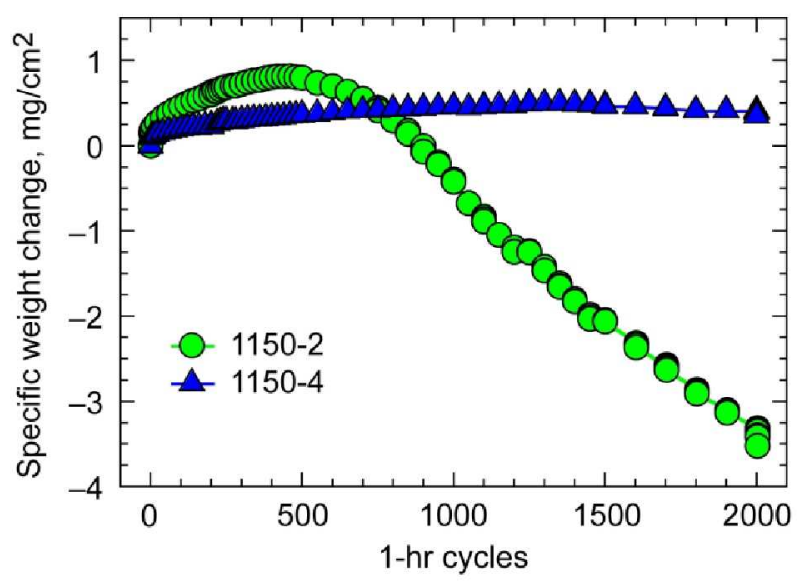

Figure 3.-Total cyclic oxidation weight change results for a Pt-aluminide coating on CMSX $4.1150^{\circ} \mathrm{C}$, for 20001 -hr cycles; 20 min. cooling cycle; held for up to 1 day to record weights. (Sample 1150-2 distinguished by excessive coating grain boundary wrinkling and local scale spallation compared to the more flat sample 1150-4 and minimal spalling).

rate afterwards, ending at $+0.4 \mathrm{mg} / \mathrm{cm}^{2}$. (Four other duplicates, tested for times between 100 to $1000 \mathrm{hr}$ as part of a broader study, showed a similar range of responses). Thus, higher growth rates and higher spallation rates are noted for sample 2 compared to sample 4 and appear to represent a range of behavior for this class of material.

The accrued amount of additional delayed spallation, obtained by holding the samples at ambient humidity for up to a day, is shown in Figure 4. These values are separate from any spallation that occurred during normal cycling, the latter being determined by initial weight measurements immediately upon removal from the furnace. The plot begins with data only after 750 cycles, when spallation became more visually pronounced. As with the total weight change in Figure 3, it is seen that sample 2 produces a noticeable, steady-state spallation, while sample 4 appears very benign. These curves imply a constant amount of delayed spallation for each weighing cycle. Accordingly, the amount of delayed spallation recorded each time the samples are removed from the furnace test is shown in Figure 5. On average, the amount lost per inspection period is $0.04 \mathrm{mg} / \mathrm{cm}^{2}$ for sample 2 and $0.00 \mathrm{mg} / \mathrm{cm}^{2}$ for sample 4 . Because of these relatively small amounts, there is considerable scatter in this plot. There is very little change for either sample, from $750 \mathrm{hr}$ to the end of the test.

The actual time dependence of the delayed spallation is shown for a number of inspection periods in Figures 6 and 7 for samples 1150-2 and 4, respectively. Here the time axis is shown as $\mathrm{t}^{1 / 2}$ in order to compress the sparse data obtained after one hour hold time. The exact starting time is problematic. Ideally, one would measure an initial weight as soon as the sample is removed from the warm, dry furnace area, held at about 100 to $120^{\circ} \mathrm{C}$. On one hand, weighing immediately would allow this residual heat in the samples to affect the balance. But on the other hand, longer preliminary cooling in ambient air would allow more delayed spallation to occur undetected. To assess the residual retained sample heat problem, an unoxidized control sample was weighed as a function of time from the cooling chamber, allowing various times of cooling before beginning the weighing. With only $15 \mathrm{sec}$ of cooling, the time it takes to remove the sample and bring it to the balance, the perceived weight was found to deviate negatively a maximum of $\sim 0.5 \mathrm{mg}$, before decaying away over the next $15 \mathrm{~min}$. However, allowing for a $2 \mathrm{~min}$. cool, this deviation was only $\sim 0.2 \mathrm{mg}$, equivalent to $\sim 0.02 \mathrm{mg} / \mathrm{cm}^{2}$ error. This latter procedure was adopted as an acceptable compromise. The residual error applies primarily to the first reading, because it is corrected for by the next recalibration of the $10 \mathrm{~g}$ standard, whose measurement is affected by the same thermal effect. 


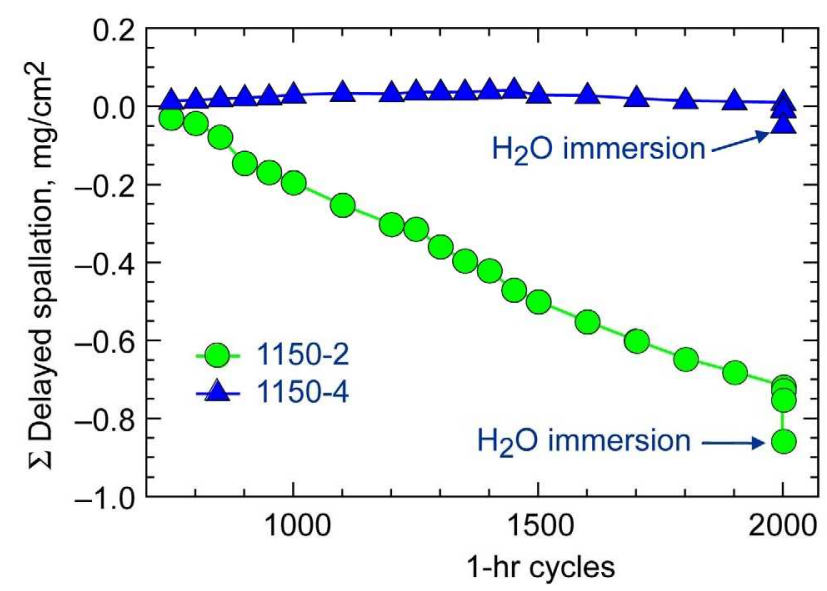

Figure 4.-Additional spallation recorded (cumulative), after the initial measurement, during hold times at ambient laboratory conditions. Delayed spallation became appreciable for sample 1150-2, beginning at about 750 cycles, but remained negligible for $1150-4$. The sequential drops in weight at 2000 cycles occurred over a $24 \mathrm{hr}$ period, followed by exposure to moisture and water immersion for $1 \mathrm{hr}$.

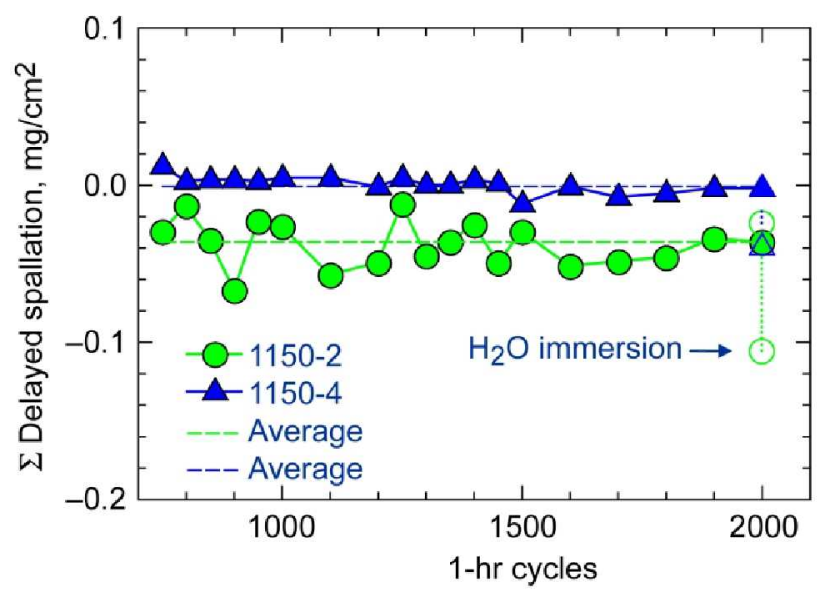

Figure 5.-Degree of delayed spallation for each individual weighing period. On average, $0.04 \mathrm{mg} / \mathrm{cm}^{2}$ additional spalling for $1150-2$; no $\left(0.00 \mathrm{mg} / \mathrm{cm}^{2}\right)$ additional spallation for 1150-4. 
Acknowledging these uncertainties for low initial readings, it is evident from Figure 6 that a progression of time delayed spallation was observed for sample 2 for times up to 1 day. Furthermore, the magnitude and decay rate was, for the most part, reasonably similar for the seven plots shown, over $1000 \mathrm{hr}$ of test time. Any initial rise in weight was due to the thermal effect on the balance. The absence of significant time delayed spallation for sample 1150-4 in Figure 7, relative to $\pm 1 \sigma$, is consistent with the all data shown previously for this highly oxidation resistant sample. This sample was always weighed after sample 1150-2, with all readings effectively recalibrated by the $10 \mathrm{~g}$ standard weight. It therefore shows little thermal transient effects even for the first few minutes.

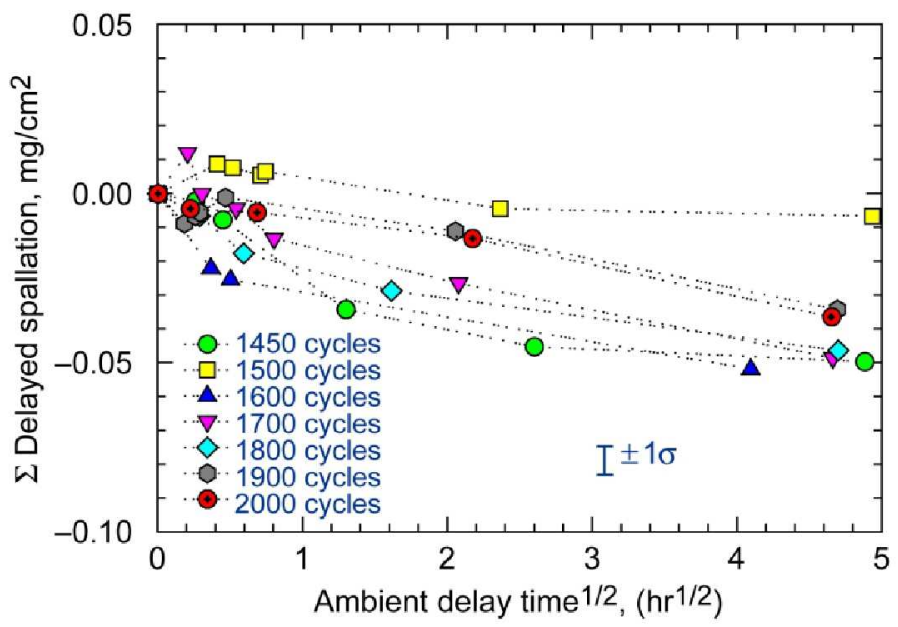

Figure 6.-Time dependency of delayed spallation for sample 1150-2 measured after various oxidation test times. (Time, weight axes relative to first weight measurement). In some cases, additional spallation continued past $5 \mathrm{hr}$ to at least 1 day after cooling. (Occasionally, residual warmth from the cooled samples produced electronic drift and an apparent weight gain for 1 to $2 \mathrm{~min}$. in the microbalance).

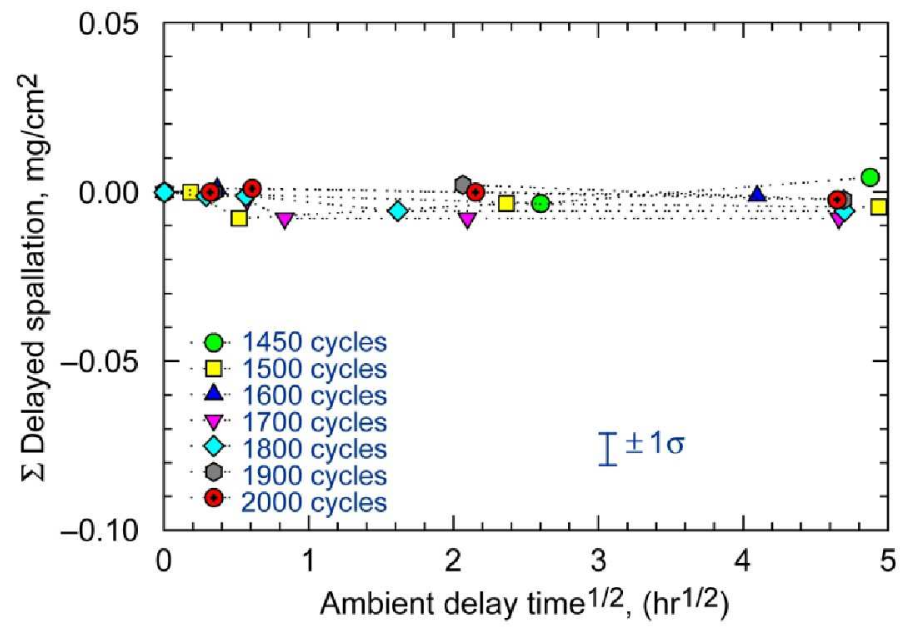

Figure 7.-Minimal time dependent delayed spallation for sample 1150-4 at various cycle times. (Time, weight axes relative to first weight measurement). Very little additional spallation continued past $1 \mathrm{hr}$. 


\section{Morphology}

Early in the study, it was noted that the coatings exhibiting higher growth rates and spallation also exhibited a roughened surface texture. Figure 8 shows an optical macrograph of the two samples, obtained under oblique lighting, after $2001-\mathrm{hr}$ cycles. It is clear that sample 2 is significantly rougher than sample 4, especially regarding the grain boundary region. For the most part the samples appeared to be a uniform matte grey, typical of $\alpha-\mathrm{Al}_{2} \mathrm{O}_{3}$ scales. Figure 9 presents optical micrographs of the surface showing detail regarding the specific spallation sites. Here sample $1150-2$ reveals delaminated scale fragments and exposed bare metal, both in the immediate vicinity of coating grain boundaries. These features increase with exposure time, beginning with apparently pure alumina at or before $200 \mathrm{hr}$, and eventually exhibiting a distinct blue-green tint to some scale fragments, as shown in the micrograph for $1000 \mathrm{hr}$. By comparison, sample 1150-4 is relatively featureless, showing a less contorted landscape with more shallow grain boundary features. There is only limited indication of scale delamination or exposed metal and relatively slight changes with continued cycling. These initial features are believed to coincide with the wide divergence in behavior in Figures 3 to 7.

The macrographs in Figure 10, obtained after 2000 1-hr cycles, confirm a higher degree of scale spallation to bare metal for sample 2. Numerous and larger spallation features are noted compared to only a few minute spall segments for sample 4 . The spalled regions extend to about $1 \mathrm{~mm}$ long for sample 2, but only as much as $0.1 \mathrm{~mm}$ for sample 4 . Water immersion produces noticeable additional spallation for sample 2, but not for sample 4. Again, it is believed that the increased spallation arose from the stress concentrations at the large curvatures of the rumpled $\mathrm{Ni}(\mathrm{Pt}) \mathrm{Al}$ coating grain boundaries.
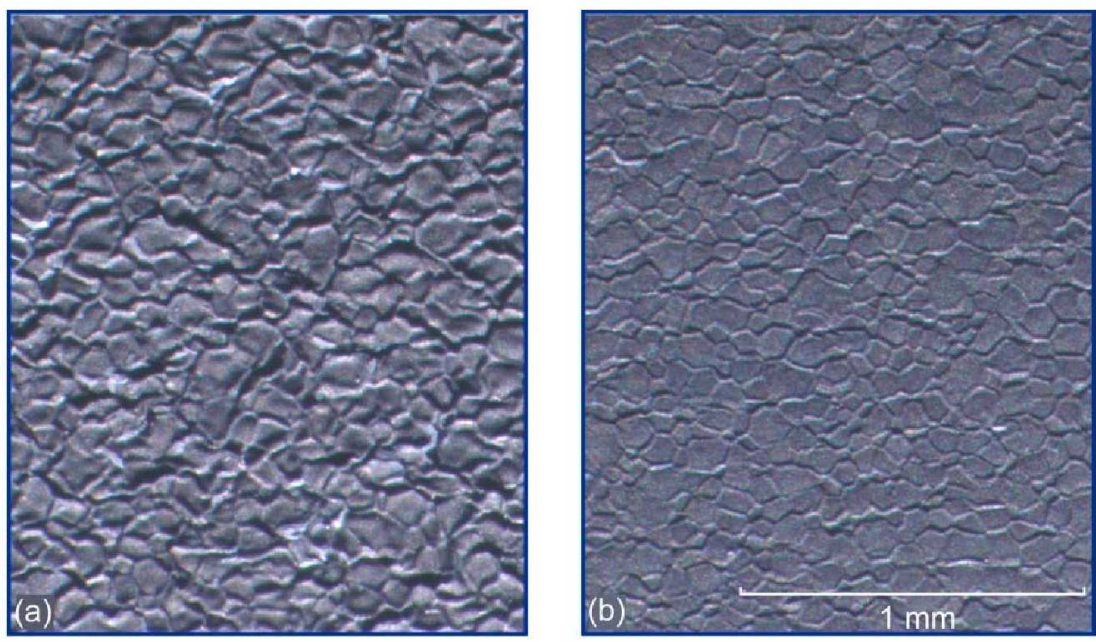

Figure 8.-Optical macrographs, obtained under oblique lighting, showing

(a) rough surface topography of the coating grains for sample 1150-2; and

(b) comparatively flat coating for sample 1150-4. (200 1-hr cycles to $1150{ }^{\circ} \mathrm{C}$ ). 

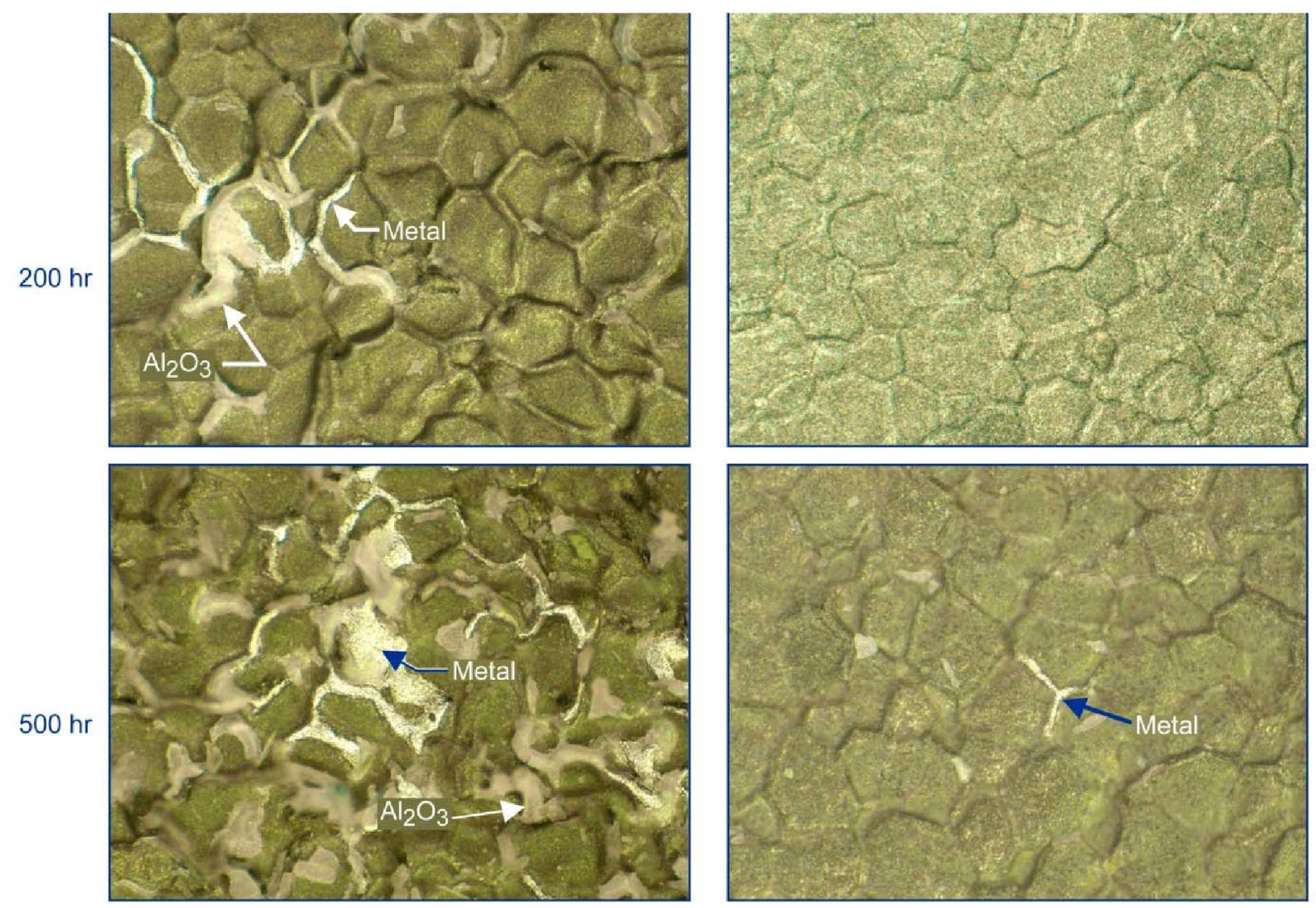

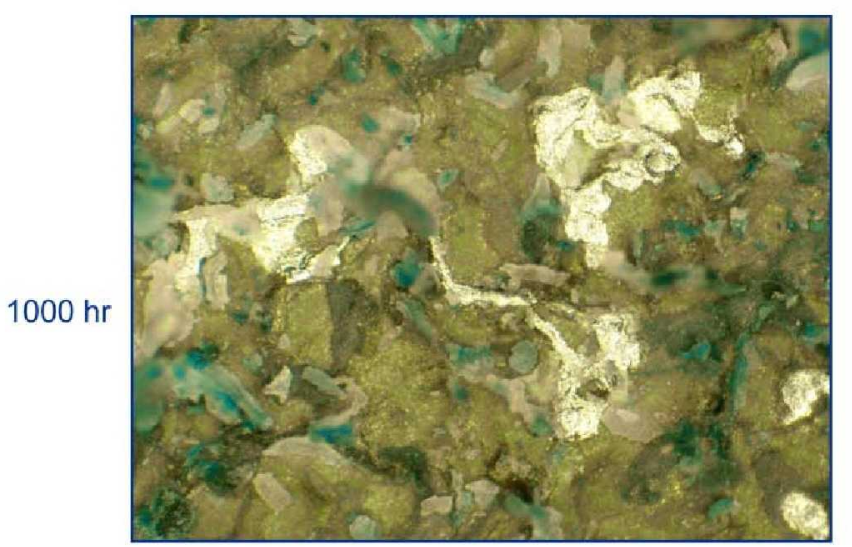

(a)

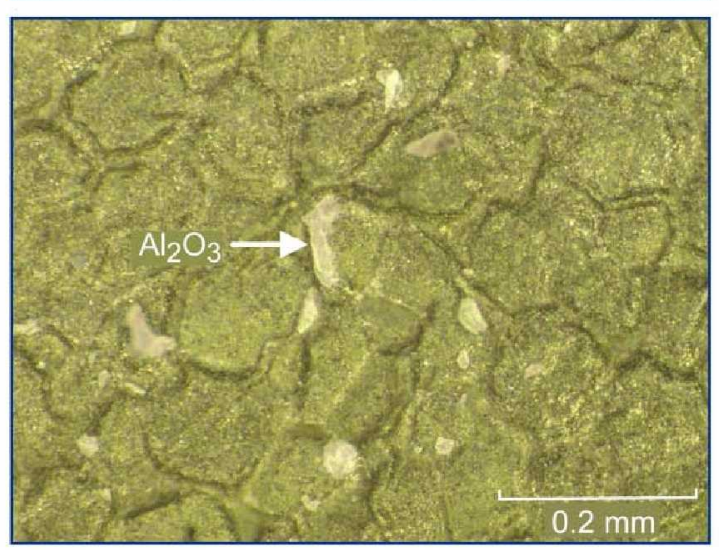

(b)

Figure 9.-Optical micrographs showing (a) detached alumina scale and exposed metal associated with deep grain boundary undulations for sample 1150-2; and (b) comparatively flat coating surface and mostly adherent scale for sample 1150-4. (at 200, 500, and 10001 -hr cycles to $1150{ }^{\circ} \mathrm{C}$ ). 

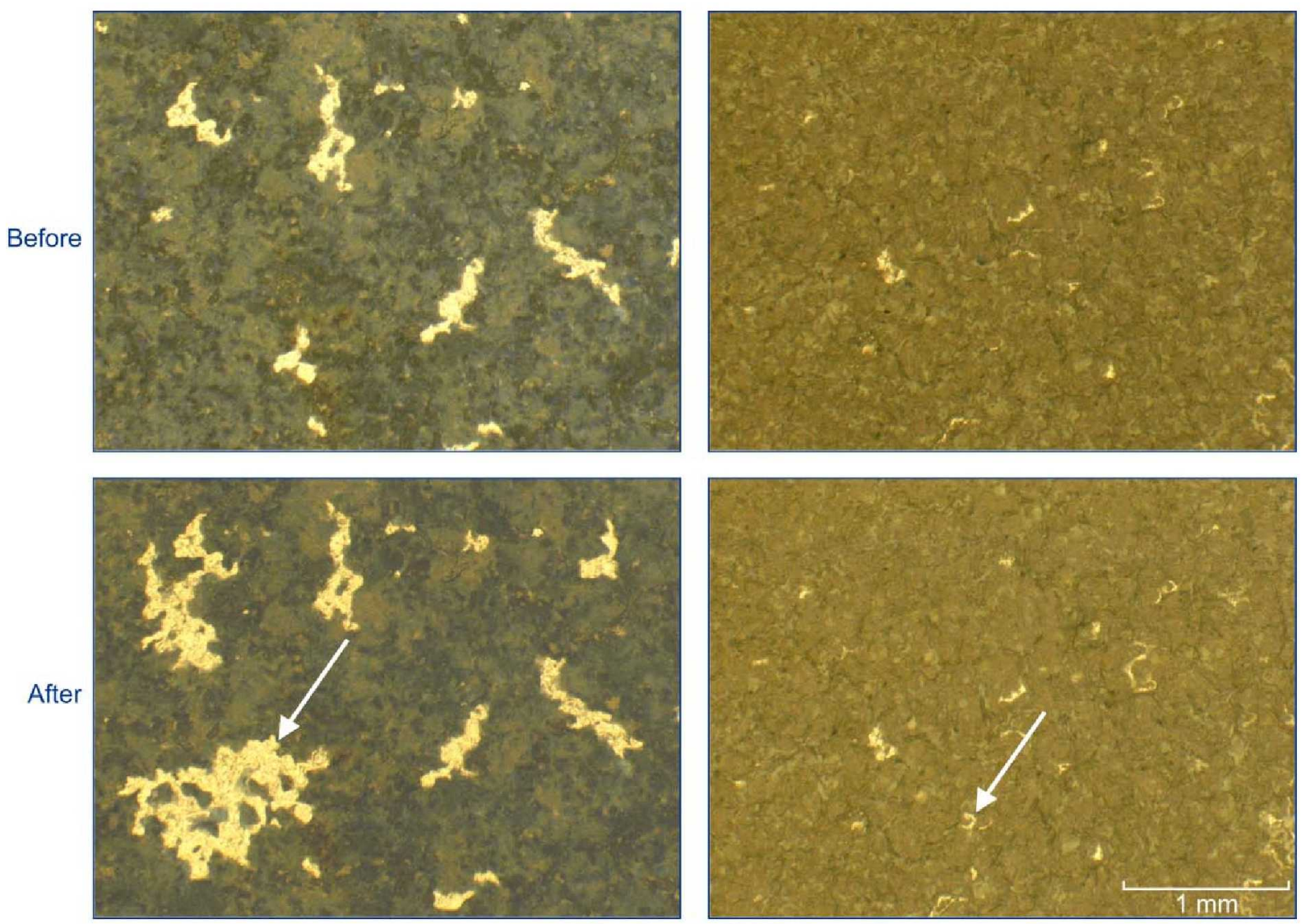

(a)

(b)

Figure 10.-Optical macrographs showing (a) appreciable spalling (arrow) to bare metal for sample 1150-2; and (b) minimal spallation (arrow) for sample 1150-4; both before and after water immersion for $1 \mathrm{hr}$. (2000 1-hr cycles to $\left.1150^{\circ} \mathrm{C}\right)$.

While these features confirm the moisture-induced trends in interfacial spallation, some of the weight change results may include the nonalumina scales that formed on sample 1150-2, as characterized by SEM/BSE/EDS studies. The low magnification BSE micrographs in Figure 11(a) reveal a large (brightest) area of spalling to bare metal for sample 1150-2, with widely varying degrees of intensity in the surrounding intact scale regions. Detailed analyses reveal typical scale-metal imprints in the spalled regions, shown to be and $\gamma$-Ni solid solution, and mixtures of, presumably, $\alpha-\mathrm{Al}_{2} \mathrm{O}_{3}$ (dark), $(\mathrm{Ni}, \mathrm{Co})(\mathrm{Al}, \mathrm{Cr})_{2} \mathrm{O}_{4}$ spinel (grey), and dispersed $(\mathrm{Ti}, \mathrm{Ta}) \mathrm{O}_{2}$ (bright) rutile oxides, as suggested by XRD analyses of similar samples. While there is some indication of layered scales, the various regions also probably relate to areas with different histories of spalling and regrowth. Characteristic EDS spectra are shown in Figure 12 for an exposed $(\mathrm{Ni}, \mathrm{Co}, \mathrm{Cr}, \mathrm{Al}, \mathrm{Pt}, \mathrm{W}, \mathrm{Ti})$ metal region and $(\mathrm{Ni}, \mathrm{Al}, \mathrm{O})$ spinel scale region. Very little interfacial spalling was observed for sample 1150-4, Figure 11(b), showing a very uniform backscatter response. However, some scale cracking, without appreciable spallation, occurred predominantly at wrinkled coating grain boundaries, exposing $\gamma-\mathrm{Ni}_{3} \mathrm{Al}$ martensite and $\gamma$-Ni solid solution. The scale was consistently $\alpha-\mathrm{Al}_{2} \mathrm{O}_{3}$, Figure 12, with only a fine dispersion of Hf-rich oxide particles decorating the ridge structure, and no indication of outer layers of Ni-rich scales. Numerous details of the SEM characterization of both samples will be presented in a companion paper (Ref. 37). 

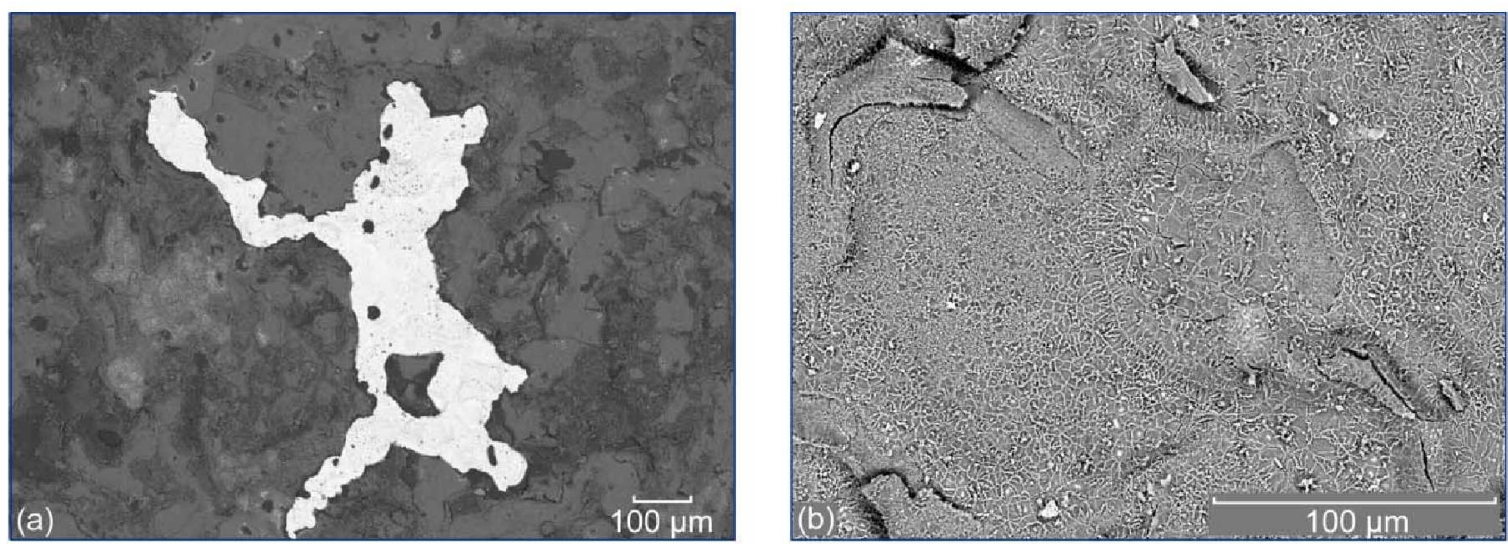

Figure 11.-Backscatter SEM micrographs of (a) sample 1150-2 showing large $500 \mu \mathrm{m}$ area of spalling to bare metal and mottled regions of intact oxide; and (b) sample 1150-4 showing relatively uniform, attached, but cracked scale. (2000 1-hr cycles to $1150^{\circ} \mathrm{C}$ ).

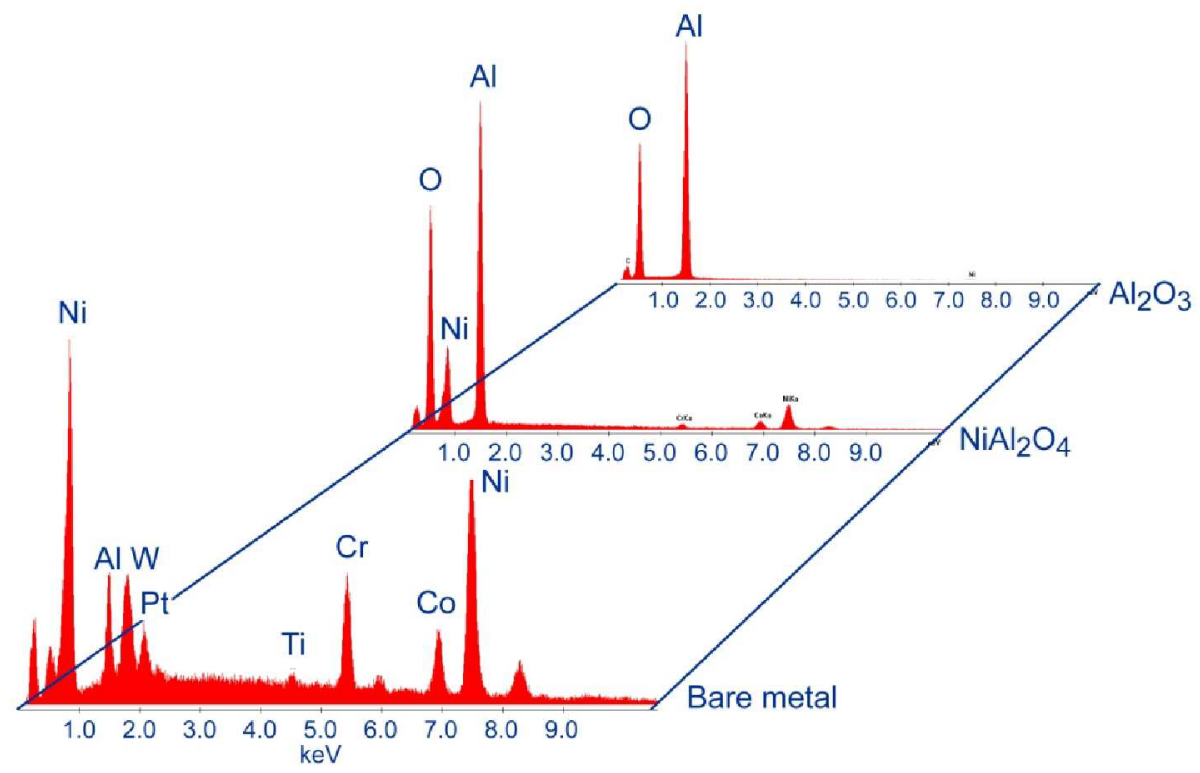

Figure 12.-EDS spectra for bright exposed metal and grey spinel scale features of sample 2 and overall uniform alumina scale on sample 4 (from Figure 11).

\section{Discussion}

The weight change data shown above indicates that a measurable amount of additional (delayed) scale spallation is possible during typical cyclic oxidation tests of a commercial oxidation resistant coating. The phenomenon takes place simply by exposing samples to a higher relative humidity away from the warm 100 to $120^{\circ} \mathrm{C}$ 'cooling' chamber of the furnace test. Not only does a relatively consistent amount of additional spallation occur, but it follows a somewhat similar trend over the span of a day, and perhaps longer. The final spallation event is due to water immersion at the end of the test. While an increase in the $\Delta \mathrm{T}$ of cooling will also increase spallation, by increasing the thermal expansion mismatch stress and stored strain energy, this cannot readily explain the time dependency of spallation. It is therefore assumed that moisture is the key factor allowing for the extra spallation, although one might postulate other time-dependent crack growth phenomena that were not operative when cooled to just above the furnace. Given the well-established sensitivity of alumina-metal interfaces toward moisture, it 
is assumed that humidity is the primary factor here. Water immersion is assumed to simply represent the extreme of 100 percent relative humidity, though one may also speculate about capillary forces of liquid water in cracks. Thus, this discussion will focus on the chemical equivalence of $\mathrm{H}_{2} \mathrm{O}_{\text {ads }}$ at the interface whether from liquid or vapor sources.

Thus, these observations are consistent with the overall mechanism of moisture-induced delayed spallation (MIDS), often observed for partially adherent alumina scales. These scales are adherent enough to withstand some degree of thermal cycling, when retained in dry environments during cooldown. This phenomenon may result from various combinations of the following factors (1) a modest sulfur content ( 0.2 to $1 \mathrm{ppmw}$ ), where partial adherence is commonplace, (2) an insufficient or nonunifom distribution of reactive elements, (3) a high degree of strain energy (i.e., thick scales), and (4) stress concentrations (due to rumpled or rough surfaces). In the present case, a high degree of adhesion is imparted by the Pt alloying addition. However, there is apparently a range of behaviors that stem from the surface roughness at the coating grain boundaries. Lower overall growth rates and higher adhesion results for the coatings that were processed relatively flat and remained smoother.

\section{Moisture Effects on Aluminide Coatings}

A single early moisture test of oxidized bulk Ni42Al in saturated $80^{\circ} \mathrm{C}$ air resulted in a loss of $0.1 \mathrm{mg} / \mathrm{cm}^{2}$ (after an $1100^{\circ} \mathrm{C}$ cyclic test in which the samples gained less that $1 \mathrm{mg} / \mathrm{cm}^{2}$ over $5001-\mathrm{hr}$ cycles) (Ref. 17). The deleterious effects of continuous exposure to moisture is significant during $1100{ }^{\circ} \mathrm{C}$ cyclic oxidation of NiAl diffusion aluminide coatings on PWA 1480 (Ref. 21), losing about $60 \mathrm{mg} / \mathrm{cm}^{2}$ after 10001 -hr cycles in 0.1 atm $\mathrm{P}\left(\mathrm{H}_{2} \mathrm{O}\right)$, as compared to just $3 \mathrm{mg} / \mathrm{cm}^{2}$ for oxidation in dry air $\left(\mathrm{P}\left(\mathrm{H}_{2} \mathrm{O}\right)=\right.$ $4 \times 10^{-6} \mathrm{~atm}$.). A similar but less severe effect was reported for the same coating on Rene'N5 (Ref. 35), exhibiting a loss of $1 \mathrm{mg} / \mathrm{cm}^{2}$ in wet air compared to only $0.1 \mathrm{mg} / \mathrm{cm}^{2}$ in dry air. However, moisture effects for $\mathrm{Ni}(\mathrm{Pt}) \mathrm{Al}$ coatings on Rene'N5 were not very apparent. Here a gain of about $0.2 \mathrm{mg} / \mathrm{cm}^{2}$ was achieved after 20001 -hr cycles in $0.1 \mathrm{~atm} \mathrm{P}\left(\mathrm{H}_{2} \mathrm{O}\right)$, as compared to a gain of $0.6 \mathrm{mg} / \mathrm{cm}^{2}$ for oxidation in dry air. Only an increase in the amount of spinel at the gas surface was observed. The general trend was discussed in terms of hydrogen-induced defects in $\mathrm{NiO}$ and $\mathrm{Al}_{2} \mathrm{O}_{3}$, resulting in faster outward transport of $\mathrm{Ni}$. It was also suggested that that spinel formation may also have been initiated by moisture-induced cracking and re-oxidation, as observed in the present study where intentional moisture was not present during oxidation.

Moisture effects are confirmed by Pint (Ref. 38) in tests of aluminide coatings and bulk $\beta$-NiAl, (plus $\gamma / \gamma^{\prime}$ and NiCrAlY) tested in 10 percent water vapor. In general the data suggests that moisture can affect spallation for aluminides, especially for alumina scales having less than optimum scale adhesion (no alloying elements of $\mathrm{Pt}, \mathrm{Hf}, \mathrm{Y}$ etc.). As in the above, water vapor was maintained in the oxidation exposure such that these samples were automatically subjected to moisture induced effects before removing them to the balance environment. Thus it is envisioned that continuous thermogravimetric analysis (CTGA) (Ref. 39) in moist environments might be a particularly useful test for more precisely determining the time-dependent nature of this phenomenon.

Delayed failure and $\mathrm{Ni}(\mathrm{Pt}) \mathrm{Al}$ bond coat oxidation was also addressed for $\mathrm{TBC}$ failure modes (Ref. 40). Here the time dependence of TBC failure was pointed out, necessitating a 2-hr hold time at room temperature between cycles to allow the effect to run its course. While differences in kinetics and TBC lifetimes were noted between as-aluminized and grit blasted (smoothed) bond coats, both failure loci exhibited substantial amounts of interfacial scale-metal debonding. Thus time dependent moistureinduced scale failure may have played some role for both surface conditions, even though TBC failure initiated at edges.

Since moisture induced interfacial failure has been implicated in these and the present study, it is informative to examine an analogous study using finely controlled relative humidity effects (Ref. 41). This work measured the interfacial shear strength of a polymeric coating on glass fibers as function of exposure time, relative humidity (RH), and temperature. Here the time factor is related to moisture transport through polymeric interfaces as opposed to hydrogen diffusion at the scale metal interface, as 
discussed later. But although the controlling mechanisms differ from delayed spallation in the atomistic details, it is still illustrative to examine the formal dependencies. Here, interface strength was found to decay exponentially with time and to be reduced as the relative humidity increased, as (RH $)^{2 / 3}$. Similar asymptotic spallation kinetics were presented in Figure 6 for delayed scale spallation. A connection to relative humidity is thus discussed below.

Our present study was performed in laboratory air. There was no intentional increase in moisture content during the delayed spallation that occurred during sample weighing. What did increase was the relative humidity in removing the sample from the cooling baffle above the furnace to ambient conditions. In order to assess relative humidity effects, we examine temperature dependent saturation values and typical relative humidity levels reported for our area. The saturation level of moisture can be estimated from the relation (Refs. 41 and 42):

$$
\begin{gathered}
P_{\mathrm{H}_{2} \mathrm{O} \text {,sat'n }}(T)=P_{\mathrm{H}_{2} \mathrm{O} \text {,sat'n }}\left(0^{\circ}\right)+k\left[\frac{T}{100}{ }^{\circ} \mathrm{C}\right. \\
\text { where, } k=0.0987 \mathrm{MPa} \\
n=3.36 \\
P_{\mathrm{H}_{2} \mathrm{O}, \text { sat'n }}\left(0^{\circ}\right)=0.00198 \mathrm{MPa}
\end{gathered}
$$

The saturation pressure (100 percent $\mathrm{RH})$ is shown in Figure 13 as a function of temperature. Thus, at $0{ }^{\circ} \mathrm{C}$ the saturation moisture content in the atmosphere is $0.00198 \mathrm{MPa},(\sim 0.020 \mathrm{~atm})$. For the local environment, weather almanacs report an average high relative humidity $(\mathrm{RH})$ of 85 percent for mornings in August, shown as the second curve, giving $0.00213 \mathrm{MPa}(\sim 0.021 \mathrm{~atm})$ at the average August temperature of $21^{\circ} \mathrm{C}$.

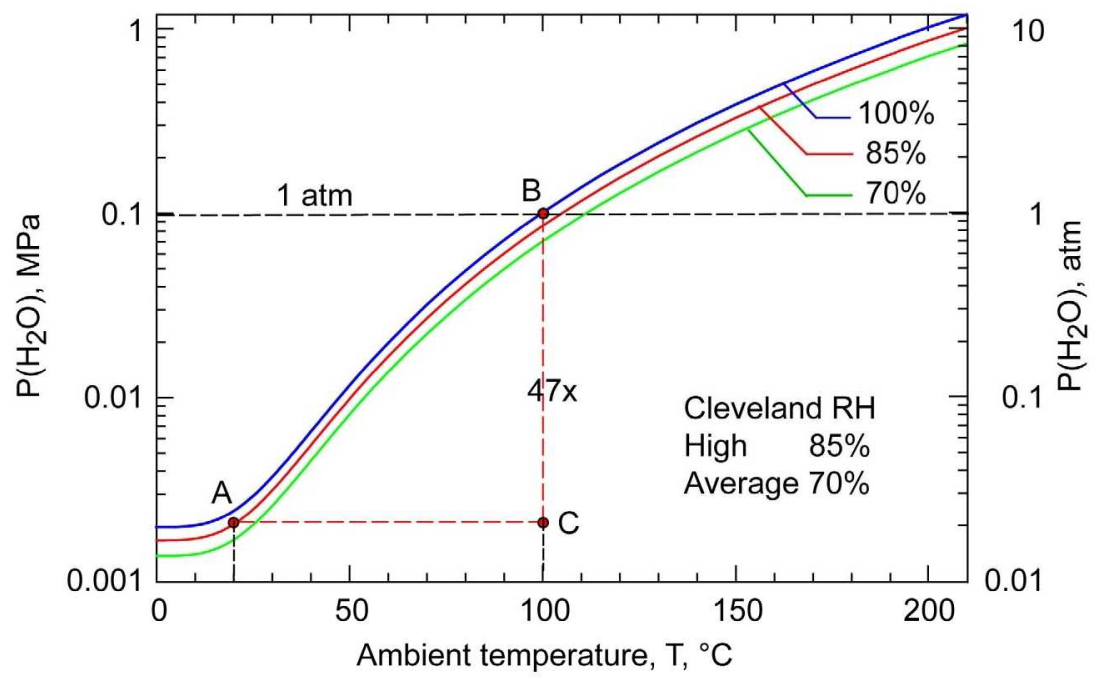

Figure 13.-Temperature dependence of water vapor pressures at saturation and typical relative humidity levels. Saturation values and moisture contents at the ambient, balance conditions $(A)$ compared to saturation values for the cooling chamber $(B)$. A relative humidity of 85 percent at ambient temperature translates to 2.1 percent at $100{ }^{\circ} \mathrm{C}(\mathrm{C})$. 
(see for example, http://www.cityrating.com/cityweather.asp?city=Cleveland)

However, the cooling chamber above the furnace is about $100^{\circ} \mathrm{C}$, while the total moisture content is fixed by that in the ambient. At $100^{\circ} \mathrm{C}$, the saturation level rises to $1 \mathrm{~atm}(0.1013 \mathrm{MPa})$, or estimated from Equation (1) as $0.1007 \mathrm{MPa}$. The relative humidity of each location can then be estimated from:

$$
\begin{gathered}
\mathrm{RH}_{\text {balance }}=\frac{P_{\mathrm{H}_{2} \mathrm{O}, 21^{\circ} \mathrm{C}}}{P_{\text {sat'n, } 21^{\circ} \mathrm{C}}}=0.85 \\
\mathrm{RH}_{\text {chamber }}=\frac{P_{\mathrm{H}_{2} \mathrm{O}, 21^{\circ} \mathrm{C}}}{P_{\text {sat'n }, 100^{\circ} \mathrm{C}}}
\end{gathered}
$$

Combining Equations (1), (2), and (3), one determines that the relative humidity in the $100{ }^{\circ} \mathrm{C}$ cooling chamber is only 2.1 percent. Consequently, removing a sample from the cooling chamber to the ambient at 85 percent essentially exposes the sample to a $40 \mathrm{x}$ increase in relative humidity. (At the $1150{ }^{\circ} \mathrm{C}$ test temperature, the saturation value is $361 \mathrm{MPa}(3570 \mathrm{~atm})$, or $1.7 \times 10^{5}$ times that at $21^{\circ} \mathrm{C}$, producing extremely low relative humidity during oxidation and no expected moisture effect.) The same exercise can be performed for colder, dryer months, but with similar conclusions.

One working hypothesis of moisture-induced delayed spallation is based on the direct access of moisture to the oxide-metal interface from cracks or pre-existing partial spallation (Refs. 22 and 43). This allows reaction of water vapor with aluminum in the alloy to form aluminum hydroxide and hydrogen according to the reaction:

$$
\mathrm{Al}_{\text {alloy }}+3\left(\mathrm{H}_{2} \mathrm{O}\right)_{\text {ads }}=\mathrm{Al}(\mathrm{OH})_{3}+3 \mathrm{H}^{+}+3 \mathrm{e}^{-}
$$

Hydrogen embrittlement of an at-risk interface is postulated as the root cause of moisture induced delayed spallation. So the question arises as to whether relative humidity or the partial pressure of water vapor is controlling the amount and activity of $\left(\mathrm{H}_{2} \mathrm{O}\right)_{\text {ads }}$ and the production of hydrogen at the interface. Unlike high temperature effects, where $\mathrm{P}_{\mathrm{H}_{2} \mathrm{O}} / \mathrm{P}_{\mathrm{O}_{2}}$ affects oxide stability, the previous analysis suggests that relative humidity may play a role for MIDS, at least in these regimes of low moisture contents $<0.1 \mathrm{~atm}$. As a general rule it has been shown that the amount of adsorbed water on metal surfaces is indeed directly related to $\mathrm{RH}$, such that $\sim 0.1$ monolayer can be expected for $\mathrm{RH}=2$ percent and $\sim 5$ to 10 monolayers for $\mathrm{RH}=80$ percent (Ref. 44). That is to say, the amount of adsorbed moisture would be predicted to increase 50-100x upon removing the sample from the furnace cooling chamber. Thus a commensurate increase in $[\mathrm{H}]^{+}$is obtained according to Equation (4), along with a corresponding decrease on interfacial strength.

\section{Roughness Effects on Spallation}

Surface roughness has been associated with bond coat oxidation failures and can be discussed in a hierarchy of severity. Broadly speaking, terms like wrinkling, ratcheting, ridges, and rumpling describe undulations of an increasing magnitude (or wavelength). Wrinkling applies to the surface instability resulting from isothermal lateral growth within the scale adhered to a metal that creeps; this occurs on a fine scale (Ref. 45). Ratcheting applies to a similar instability caused by thermal expansion mismatch stresses during cycling and an irreversible plastic strain that occurs on cool down as the rigid low expansion oxide scale forces the metal to extend (Ref. 16). Ridges are the $\beta$-NiAl grain boundary surface hillocks (and valleys) resulting from the diffusion aluminizing process. And rumpling has recently been shown to be caused by cyclic stresses arising from differential thermal expansion mismatch between the 
coating, primarily at temperatures above $1000^{\circ} \mathrm{C}$ (Ref. 46). Other strain instabilities, arising from a nonuniform dispersion of $\beta$-NiAl to $\gamma-\mathrm{Ni}_{3} \mathrm{Al}$ diffusional phase transformations, often associated with grain boundaries (Refs. 47 and 48), and reversible martensitic transformations in Ni(Pt)Al (Refs. 49 to 52) have previously been suggested as factors encouraging scale and TBC failures. It would appear that cyclic creep deformation and exacerbated bond coat grain boundary topographical excursions contribute to the major detrimental effect here, with the stress concentrations at sharp curvatures initiating scale failure.

In any case, variations in $\mathrm{Ni}(\mathrm{Pt}) \mathrm{Al}$ coating performance, based on surface roughness (rumpling and grain boundary ridges), have been observed previously, analogous to the present situation (Ref. 53). Here performance was categorized by TBC cyclic life, though connections were drawn to bond coat oxidation properties and the propensity for scale spallation to initiate at grain boundary ridges. Again, no underlying cause for the variations was discovered, but implications were drawn regarding deleterious grain boundary chemistry. This unfortuitous occurrence of grain boundary ridges and their role in scale and TBC spallation has been expounded further (Ref. 54). Here the features were correlated by coating batch, though not specifically connected to the causative factor. Indeed, others have correlated TBC life with bond coat roughness and the rate of rumpling, both being a direct function of scale thickness (oxidation time) and lateral growth strains (Refs. 55 and 56). Variation in $\mathrm{Ni}(\mathrm{Pt}) \mathrm{Al}$ cyclic behavior can be seen in other studies (Refs. 57 and 58).

In any event, the wide difference in behavior between the two samples provides a troubling subtext to this study, at least at this elevated test temperature. At present there is no known difference in pedigree between the two coatings. They were nominally processed as replicates in the same coating runs. Since no characterization was performed during the individual processing steps, it is impossible to trace back potential factors, such as initial sulfur content. It can only be said that the two samples exhibit an apparent difference in surface roughness early on in test, due in part to the as-coated topography. These Ni(Pt)Al grain boundary ridges initiate scale spallation and result in much less protective behavior for sample 1150-2, although some indications for boundary wrinkling and spalling has eventually become apparent for sample 1150-4 after 2000 cycles. Given these limitations, one can only speculate on an explanation for decreased adhesion if there were different substrate sulfur contents (as seen in Reference 59) or for increased oxidation resistance with higher Hf dopant contents (as seen in References 60 and 61).

In the present work, this propensity for spallation is also exhibited by the degree of moisture induced delayed spallation. This is consistent with the overall attributes of MIDS, which require partially compromised scale adhesion before becoming active. Some access to the oxide-metal interface is also required, as would happen for the grain boundary wrinkling-induced fractures. The latter is only enabled by the substantial stored strain energy resulting from extensive oxidation. Lower temperatures would result in reduced wrinkling and considerably less spallation over much longer times.

The appearance of ridge-related spallation as early as $200 \mathrm{hr}$ (Fig. 9) may play some role in initiating delayed (desktop) failure of EB-PVD TBC's on Ni(Pt)Al coated Rene'N5 discs (Ref. 31). Here, similar $1150{ }^{\circ} \mathrm{C}$ furnace cycling produced TBC failure at the scale-metal interface between 220 to $420 \mathrm{hr}$. Water drop induced TBC failures were produced at 260 to $300 \mathrm{hr}$, while $750 \mathrm{hr}$ were required for these effects on scale spallation to be quantified in the present study. In one sense the TBC can be seen to restrain scale spallation for a while, since it is behaving as a rigid top layer and would serve to reduce rumpling. In another sense the TBC CTE mismatch contributes to the strain energy driving spallation of the TBC and attached scale. In general terms, moisture can be seen as a factor for TBC failure when it has access to and weakens the metal interface of highly stressed scales.

\section{Concluding Remarks}

Commercial platinum aluminide coatings were oxidized at $1150^{\circ} \mathrm{C}$ for 20001 -hr cycles. Weight change was monitored throughout the test and occasionally as a function of hold time under ambient, room temperature conditions. The relative humidity was estimated to be increased by a factor of $40 \mathrm{x}$ from 
the warm 'cooling' chamber of the furnace to the ambient balance conditions. The degree of adsorbed moisture and potential interfacial hydrogen production was proposed to increase proportionally.

Moisture-induced delayed spallation was found to proceed, at a decreasing rate, for up to one day after cooldown. This occurred preferentially for the overly stressed alumina scale regions on the sample having grain boundary ridges typical of aluminide coatings, progressing after extensive pre-cycling. This is consistent with many previous observations of moisture enhanced or delayed scale spallation for conventional aluminides and single crystal superalloys. But it is less widely appreciated that such phenomena may also occur for commercial platinum aluminide coatings. This has implications for delayed TBC failure (desktop spallation) when platinum aluminide bond coats are used.

Another practical ramification is to recall that cyclic data is subject to a certain amount of variation based on specific experimental protocols: e.g., the temperature reached each cooling cycle, the frequency of inspection, and the residence time at ambient conditions. Some attention to consistent weighing procedures is again noted and the utility of controlled humidity environments is acknowledged.

\section{References}

1. J.C. Schaeffer, G.M. Kim, G.H. Meier, and F.S. Pettit, in The Role of Active Elements in the Oxidation Behavior of High Temperature Metals and Alloys, E. Lang, ed., Elsevier (1989), 231-267.

2. B. Gleeson, N. Mu, and S. Hayashi, J. Mater. Sci. (2009) in press.

3. B. Gleeson, W. Wang, S. Hayashi, and D. Sordelet, Materials Science Forum, 461-464 (2004) 213-222.

4. E. Copland, Thermodynamic Effect of Platinum Addition to $\beta-\mathrm{NiAl}$ : An Initial Investigation. NASA/CR - 2005-213330.

5. F. Qin, C. Jiang, J.W. Anderegg, C.J. Jenks, B. Gleeson, D.J. Sordelet, and P.A. Thiel, Surf. Sci. 601 (2007) 376-380.

6. Y. Cadoret, M.P. Bacos, P. Josso, V. Maurice, P. Marcus, and S. Zanna, Materials Science Forum, 461-464 (2004) 247-254.

7. P.Y. Hou and K.F. McCarty, Scripta mater., 54 (2006) 937-941.

8. P.Y. Hou and K. Priimak, Oxidation of Metals, 63 (2005) 113-129.

9. P.Y. Hou and V.K. Tolpygo, Surf. Coat. Technol., 27 (2007) 623-627.

10. D. Monceau et al., Oxid. Met., in press (2009).

11. A.B. Anderson, C. Ravimohan, and S.P. Mehandru, Surf. Sci., 183 (1987) 438- 448.

12. R. Yu and P.Y. Hou, Appl. Phys. Lett., 91 (2007) 011907:1-3.

13. A. Gauffier, E. Saiz, A.P. Tomsia, and P.Y. Hou, J. Mater. Sci., 42 (2007) 9524-9528.

14. P.Y. Hou, Annu. Rev. Mater. Res. 38 (2008) 275-298.

15. L. Hu, D. Hovis, P.Y. Hou, J.L. Smialek, and A.H. Heuer, in preparation.

16. M.Y. He, A.G. Evans, and J.W. Hutchinson, Acta mater. 48, 2593-2601 (2000).

17. J.L. Smialek, Met. Trans., 9A, (1978) 308.

18. J.L. Smialek, in N.L. Peterson Mem. Symp. Proc. on Oxidation and Associated Mass Transport, TMS-AIME, Warrendale, PA (1986) 297-313.

19. D.R. Sigler, Oxid. Met., 40 (1993) 555-583.

20. M.A. Smith, W.E. Frazier, and B.A. Pregger, Mat. Sci. Eng., 203 (1995) 388.

21. R. Janakiramanan, G.H. Meier, and F.S. Pettit, Met. Trans., 30A (1999) 2905-2913.

22. J.L. Smialek, "Moisture-Induced Delayed Spallation and Interfacial Hydrogen Embrittlement of Alumina Scales," NASA/TM - 2005-214030, 29 pages (December, 2005).

23. J.L. Smialek, Mater. Sci. Forum, 595-598 (2008) 191-198.

24. D.R. Clarke, R.J. Christensen, and V. Tolpygo, Surf. Coat. Technol., 94-95 (1997) 89-93.

25. J.L. Smialek and G.N. Morscher, Mat. Sci. Engineer. A 332 (2002) 11-24.

26. V. Tolpygo, D.R. Clarke, Mater. Sci. Eng. A278 (2000) 142-161. 
27. V. Sergo and D.R. Clarke, J. Am. Ceram. Soc., 81 [12] (1998) 142-161.

28. X. Peng and D.R. Clarke, J. Am. Ceram. Soc., 83, [5] (2000) 1165-1170.

29. J.L. Smialek, "Scale Adhesion, Sulfur Content, and TBC Failure on Single Crystal Superalloys," in Ceramic Engineering and Science Proceedings, American Ceramic Society, Westerville, OH, 23, 4 (2002) 485-495.

30. J.L. Smialek, J. Therm. Spray Technol., 13 (2004) 66-75.

31. J.L. Smialek, Dongming Zhu, and Michael D. Cuy, Scripta Materialia, 59 (2008) 67-70; also "Moisture-Induced Delamination Video of an Oxidized Thermal Barrier Coating," NASA/TM2008-215210, (April, 2008).

32. M. Rudolphi, D. Renusch, and M. Schütze, Scripta mat., 59 (2008) 255-257.

33. Y. Cadoret, A. Raffaitin, "Development and Use of High Temperature Coatings and TBC Bond Coats for Gas Turbine Engines," presented at Workshop on High Temperature Corrosion and Protection for Aeronautic Applications, D. Monceau, Chair, U. Toulouse, May 16, 2008.

34. J.L. Smialek, unpublished research, NASA Glenn Research Center, 2009.

35. M.C. Maris-Sida, G.H. Meier, and F.S. Pettit, Met. Trans., 34A (2003), 2609-2619

36. J.A. Nesbitt and J.L. Smialek, unpublished research, NASA Glenn Research Center, 2008.

37. J.L. Smialek and A. Garg, unpublished research, NASA Glenn Research Center, 2009.

38. B.A. Pint, J.A. Haynes, Y. Zhang, K.L. More, and I.G. Wright, Surf. Coat. Tech. 201 (2006) $3852-3856$.

39. D. Monceau and D. Ponquillon, Oxid. Met. 61 (2004) 143.

40. V.K. Tolpygo and D.R. Clarke, and K.S. Murphy, Surf. Coat. Technol., 146-147 (2001) 124-131.

41. S.T. Shiue, H.C. Lin, T.Y. Shen, and H.C. Hseuh, Mat. Sci. Eng. A 434, (2006) 202-206.

42. J.H. Keenan, F.G. Keyes, P.G. Hill, J.G. Moore, Steam Tables: Thermodynamic Properties of Water Including Vapor, Liquid, and Solid Phases, Wiley New York, 1978.

43. J.L. Smialek, JOM, (2006) 1, 29-36.

44. V. Kucera and E. Mattson, "Atmospheric Corrosion," in Corrosion Mechanisms, F. Mansfield, ed., Marcel Dekker, New York, (1989) 211-284.

45. V.K. Tolpygo and D.R. Clarke, Acta mater. 46 (1998) 5153.

46. V.K. Tolpygo and D.R. Clarke, Surf. Coat. Technol., (2009) in press.

47. V.K. Tolpygo and D.R. Clarke, Acta mater. 48 (2000) 3283-3293.

48. V.K. Tolpygo and D.R. Clarke, Acta mater. 2004 (52), I and II, 5115-5141.

49. Y. Zhang, J.A. Haynes, B.A. Pint, I.G. Wright, and W.Y. Lee, Surf. Coat. Technol., 163-164 (2003) 19-24.

50. M.W. Chen, R.W. Ott, T.C. Hufnagel, P.K. Wright, and K.J. Hemker, Surf. Coat. Technol., 163164 (2003), 25-30.

51. D. Pan, M.W. Chen, P.K. Wright, and K.J. Hemker, Acta Mat. 51 (2003) 2205-2217.

52. D.J. Sordelet, M.F. Besser, R.T. Ott, B.J. Zimmerman, W.D. Porter, and B. Gleeson, Acta mater. 55 (2007) 2433-2441.

53. V.K. Tolpygo and D.R. Clarke, Surf. Coat. Technol., 163-164 (2003), 81-86.

54. V.K. Tolpygo and D.R. Clarke, Surf. Coat. Technol., 200 (2005) 1726-1281.

55. S. Sridharan, L. Xie, E.H. Jordon, M. Gell, and K.S. Murphy, Mat. Sci. Eng., A393, (2005) 51-62.

56. M. Wen, E.H. Jordon, and M. Gell, Surf. Coat. Technol., 201 (2006) 3289-3298.

57. N. Vialas and D. Monceau, I, Oxid. Met. 66 (2006) 155-189: II, Oxid. Met., 68 (2007) 223-242.

58. K.S. Murphy, Howmet Corp., private communication, 2008.

59. J.A. Haynes, Scripta mater. 44 (2001) 1147-1152.

60. V.K. Tolpygo, K.S. Murphy, D.R. Clarke, Acta mat. 2008 (56), 489-499.

61. B.A. Pint, J.A. Haynes, K. More, P.K. Wright in: Green K.A., Pollock T.M., Harada H., Howson T.E., Reed R.C., Shirra J.J., Walston S., editors. Superalloys 2004: The Minerals, Metals and Materials Society, 2004. p. 597. 


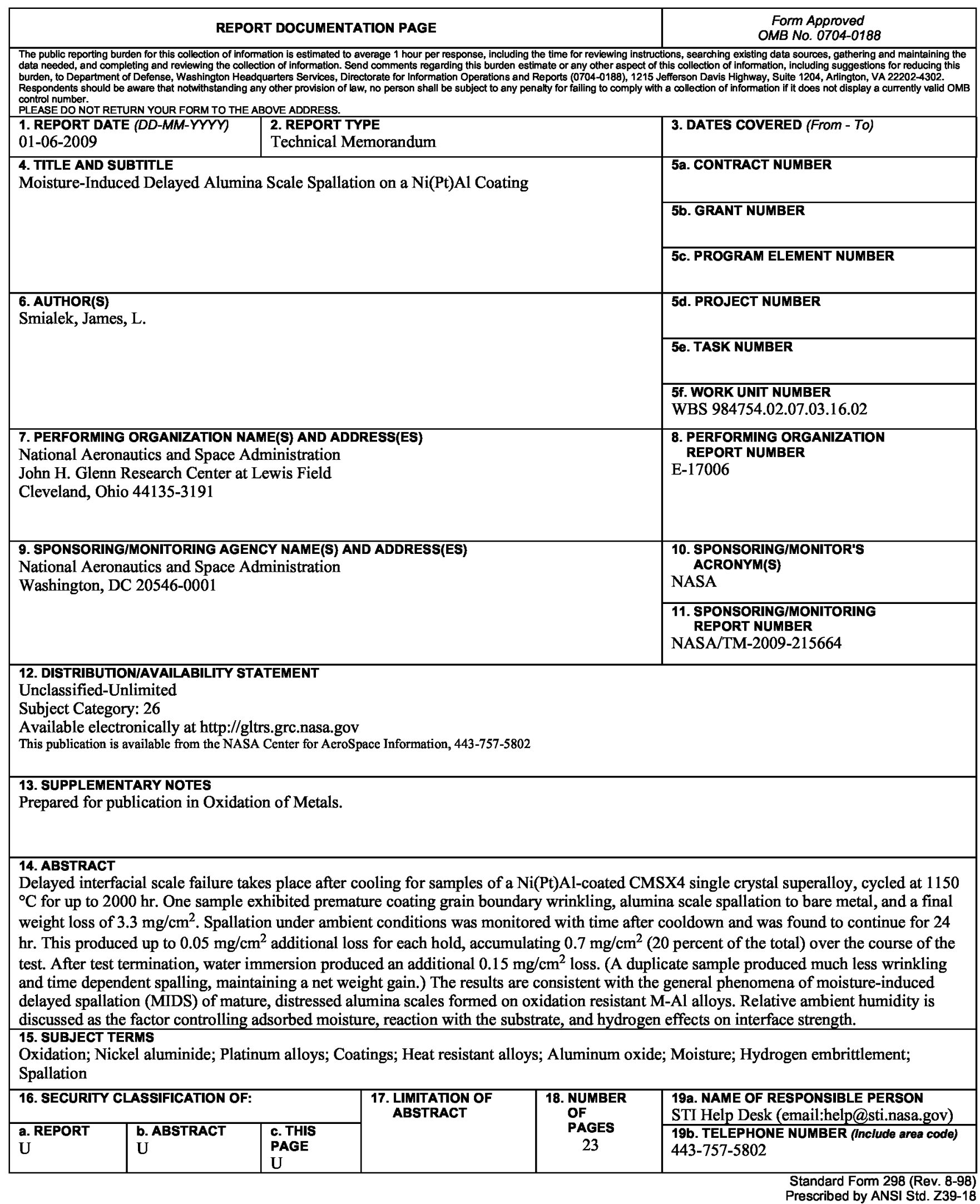



